\title{
Increasing End-of-Life Recovery Profit using Axiomatic Design Principles: A Case of Mobile Phone Keypad
}

\author{
Lee Guang Beng ${ }^{a}$ and Badrul Omar ${ }^{b}$
}
Faculty of Mechanical And Manufacturing Engineering, Universiti Tun Hussein Onn Malaysia, 86400 Parit Raja, Batu Pahat, Johor, Malaysia.
ahd110141@siswa.uthm.edu.my, bbadrul@uthm.edu.my

Keywords: axiomatic design, design for EOL management, recovery profit, product end-of-life.

\begin{abstract}
Application of axiomatic design (AD) for the purpose of enhancing end-of-life recovery potential of a product has been the main focus of this paper. To demonstrate the usage of AD in this particular area, a case study that involves keypad assemblies of mobile phones is presented. The functional requirements (FR) of the two assemblies were defined differently (only Handset 2 involves refurbishment-related FRs). Using evaluation approach presented by Kwak and Kim (2010), it can be observed that when recovery-related requirements are omitted, application of AD produces a keypad assembly that fulfills the FRs derived from customer needs with more complicated product architecture. In contrast, when recovery-related FRs are included during problem definition using axiomatic approach, the disassemblability of the resulted keypad is improved and thus increasing recovery potential in the event of replacing defective keypad, while satisfying product-related FRs.
\end{abstract}

\section{Introduction}

Nowadays, disposal can no longer be the primary retirement strategy for products that reach their end-of-life (EOL), due to stronger stewardship for product retirement urged by environmental regulations. To reduce waste and save resources, EOL management i.e. the process of converting EOL products into re-marketable products, components, or materials, can be a useful solution [1].

Other than environmental regulations, profit is another essential motivator for companies to perform product recovery. While complying with legislation, it is also possible to gain some economic advantage when companies undertake product recovery [1,2]. The most important factor that impacts a product's recovery profit is the design of the product [1,3]. EOL management should be considered in design stage in order to ensure that the product has high recovery potential [2].

\section{Axiomatic Design Principles}

Most of product or systems failures can be attributed to either or a combination of the following: (1) excessive functional requirements (FRs), (2) continuing alterations to FRs, (3) wrong design decision, and (4) inability to identify mistakes early enough to rectify them. The basic premise of axiomatic design (AD) is that there are basic principles that govern design decision in order to avoid the foregoing situations. AD is a design model based on product attribute in which two axioms are utilized for design. Axiom 1 emphasizes the importance of maintaining the independence of functional requirements while Axiom 2 suggests that the design that has the smallest information content is the best design. Within this axiomatic system, designs are classified into three types, namely uncoupled, coupled, and decoupled designs [4]. Readers are directed to these literatures for better understanding on AD principles [4-6].

\section{Case Study}

In this section, application of AD to increase a product's recovery potential is presented by using two sets of functional requirements and design parameters, which ultimately produce two different 
configurations of handsets, and in turn impact their respective recovery profit. This case study is intended to demonstrate the usage of axiomatic system in producing more recoverable products and to reveal how an architectural difference can lead to discrepancy in recovery profit. It concentrates only on the mechanical design and issues regarding other areas (e.g. software design, circuit design) are not taken into account. All the parameter values used in this study are deterministic and may not be realistic. To avoid complication, this study only emphasizes on the keypad assembly and refurbishment of faulty keypads.

To produce a good design of mobile phone keypad, the essential functional requirements (FRs) and design parameters (DPs) are listed in Fig. 1. This information is adopted from several patent documents that are related to keypad design [7-9]. Note that $\mathrm{FR}_{11}$ is further decomposed into $\mathrm{FR}_{111}$ because of the following reasoning. To allow single hand manipulation, the size of a keypad should be close to the dimensions given but its layout can range from $4 \times 3+\mathrm{e}$ up to $8 \times 5+\mathrm{e}$, depending on the size selected. Nonetheless, if the keypad has to be small, the best arrangement would be as stated, $\mathrm{X} \times 3+\mathrm{e}$ [7]. Therefore, $\mathrm{FR}_{11}$ and $\mathrm{FR}_{111}$ are hierarchical and the value of $\mathrm{DP}_{11}$ has to be fixed before moving on to determine $\mathrm{FR}_{111}$.

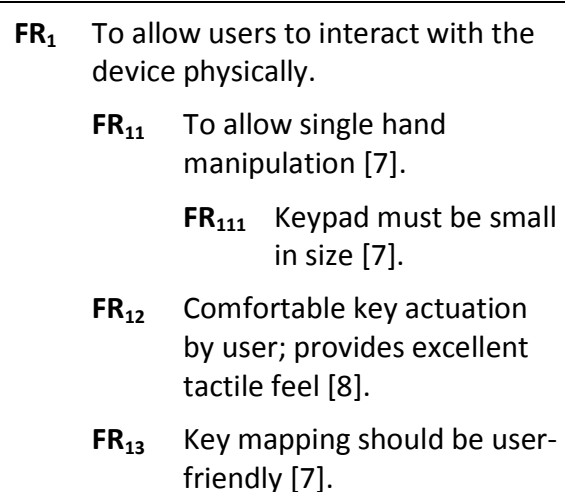

$\mathbf{F R}_{\mathbf{1}}$ To allow users to interact with the device physically.

$\mathbf{F R}_{\mathbf{1 1}}$ To allow single hand manipulation [7].

$\mathbf{F R}_{111}$ Keypad must be small in size [7].

$\mathbf{F R}_{\mathbf{1 2}}$ Comfortable key actuation by user; provides excellent tactile feel [8].

$\mathbf{F R}_{\mathbf{1 3}}$ Key mapping should be userfriendly [7].

(a)

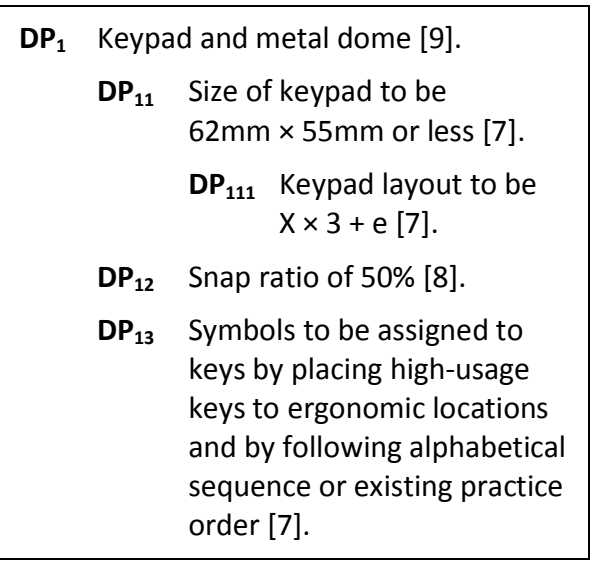

(b)

Fig. 1 (a) \& (b): Functional requirements and design parameters of a mobile phone keypad.

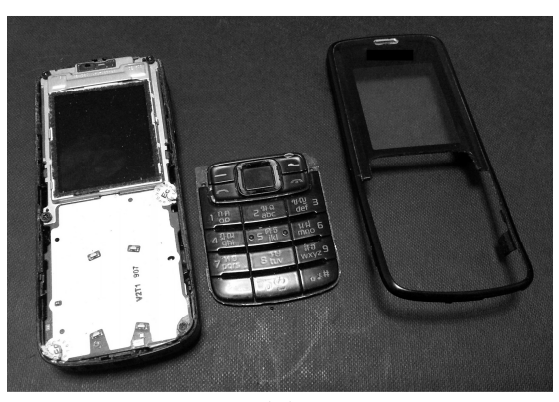

(a)

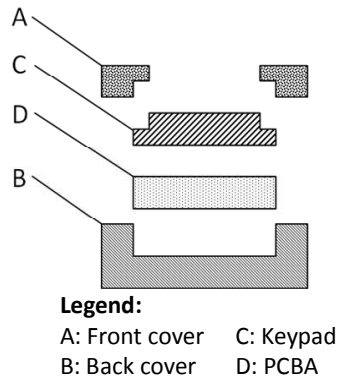

(b)

Fig. 2 (a) \& (b): The design of Handset 1 and its diagrammatic representation.

As shown in Fig. 2(a), Handset 1 is an example of mobile phone that has a keypad which satisfies all the specified FRs. The assembly schematic of Handset 1 is depicted in Fig. 2(b). In the event of replacing a faulty keypad, removal of front cover is inevitable. From a disassemblability point of view, this is an additional operation that costs more labor hour and will in turn impacts the recovery profit. Nevertheless, issues regarding product recovery are not considered as part of the functional requirements in this section and keypad design of Handset 1 still fulfills the product FRs. However, the questions remain on the disassemblability issues. Can the design be improved in terms of recovery potential? Will this configuration cause difficulties during recovery operations?

In addition to the product-related FRs, new FRs (denoted $\mathrm{FR}_{2}$ ) are included to specify the requirements to produce a recoverable keypad design. To fulfill the $\mathrm{FR}_{2}$ (and its sub-FRs), $\mathrm{DP}_{2}$, 
$\mathrm{DP}_{21}$, and $\mathrm{DP}_{22}$ are determined by following a series of guidelines for design for disassembly and recycling [10]. A list of additional FRs and DPs, together with original product-related FRs and DPs is presented in Fig. 3. Note that $\mathrm{FR}_{2}$ can also be decomposed further and in this case, value of $\mathrm{DP}_{2}$ is first determined and $\mathrm{FR}_{2}$ is then further decomposed into $\mathrm{FR}_{21}$ and $\mathrm{FR}_{22}$, which are satisfied by $\mathrm{DP}_{21}$ and $\mathrm{DP}_{22}$ respectively. As illustrated in Fig. 4(a), an example of Handset 2 with simpler removal of keypad is presented. The detachment of keypad can be achieved without having to remove the front cover beforehand. This creates an opportunity to reduce operation cost and in other words, recovery profit is likely to be increased. Fig. 4(b) depicts the representation of Handset 2 assembly.

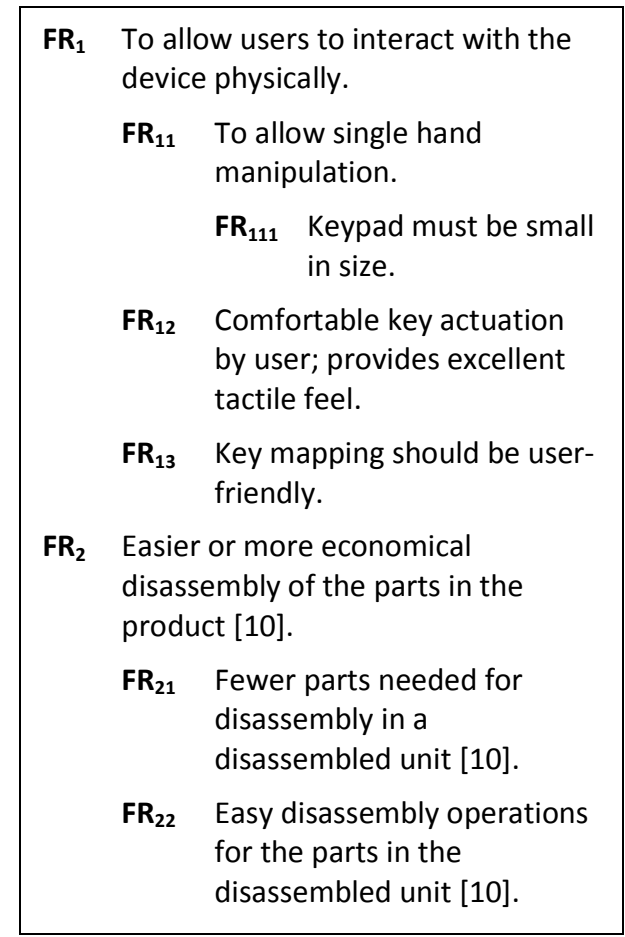

(a)

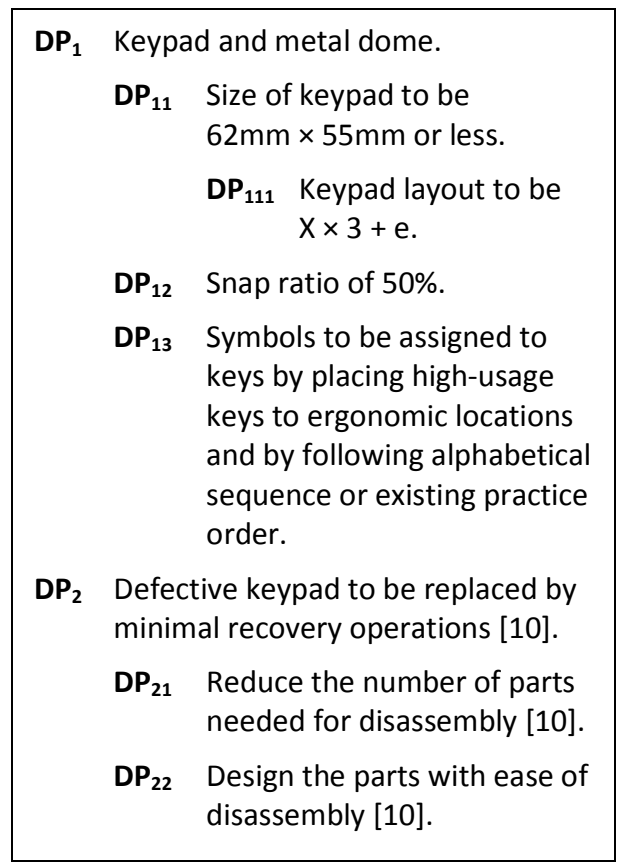

(b)

Fig. 3 (a) \& (b): Additional $\mathrm{FR}_{2}$ and $\mathrm{DP}_{2}$ are added to the original set of FRs and DPs.

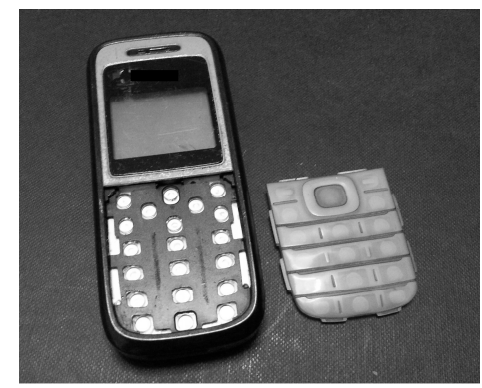

(a)

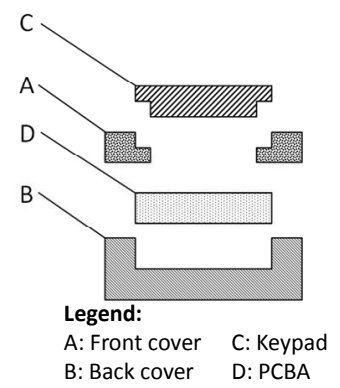

(b)

Fig. 4 (a) \& (b): The design of Handset 1 and its diagrammatic representation.

\section{Evaluation of Design}

A series of design evaluation is carried out in this section. Both configurations of Handset 1 and Handset 2 are analyzed using the methodology presented by Kwak and Kim. This approach is used in this study because of its ability to address recovery network parameters, which is a missing feature in previous methodologies presented in other existing literatures [2]. The necessary recovery operations are represented in the form of transition matrix. The proposed mathematical model is then used to calculate the overall recovery profit of each design configuration.

Before commencing the evaluation of design, a set of assumptions has to be listed down. Since the major difference of Handset 1 and Handset 2 configurations is the assembly sequence, mass of 
individual parts used in both configurations are assumed to be identical $(0.085 \mathrm{~kg} / \mathrm{handset}$, $0.01 \mathrm{~kg} / \mathrm{keypad}$ ) and the total amount of returned products is 5000 for each handset. Transportation costs RM 0.385/unit distance/weight. Selling a refurbished handset will contribute to a revenue of RM 75 whereas RM 0.002 is the revenue of selling a defective keypad to secondary market. Recovery plant is $4 \mathrm{~km}$ and $1 \mathrm{~km}$ from collection point and demand sites respectively.

Transition matrices are used to illustrate the necessary operations to refurbish a defective keypad for both Handset 1 and Handset 2. Fig. 5 shows the transition matrices of both handsets and together with the associated cost of each operation. Considering the first column of Fig. 5(a), the disassembly process consumes an $\mathrm{ABC} * \mathrm{D}$ assembly and produces two individual parts of $\mathrm{A}$ and $\mathrm{BC}^{*} \mathrm{D}$. Note that asterisks in the matrices denote defective parts. The result of evaluation is shown in Table 1.

\begin{tabular}{|l|c|c|c|c|c|}
\hline \multirow{2}{*}{ Operations } & 1 & 2 & 3 & 4 & 5 \\
\cline { 2 - 6 } States & \multicolumn{2}{|c|}{ Disassembly } & \multicolumn{2}{c|}{ Spare } & \multicolumn{2}{|c|}{ Reassembly } \\
\hline$A B C^{*} D$ & -1 & 0 & 0 & 0 & 0 \\
\hline$A B C D$ & 0 & 0 & 0 & 0 & 1 \\
\hline$B C^{*} D$ & 1 & -1 & 0 & 0 & 0 \\
\hline$B C D$ & 0 & 0 & 0 & 1 & -1 \\
\hline$B D$ & 0 & 1 & 0 & -1 & 0 \\
\hline$A$ & 1 & 0 & 0 & 0 & -1 \\
\hline$C$ & 0 & 0 & 1 & -1 & 0 \\
\hline$C^{*}$ & 0 & 1 & 0 & 0 & 0 \\
\hline
\end{tabular}

\begin{tabular}{|l|c|c|c|c|c|}
\hline Operation & 1 & 2 & 3 & 4 & 5 \\
\hline Cost (RM) & 0.10 & 0.05 & 0.95 & 0.05 & 0.085 \\
\hline
\end{tabular}

(a) Handset 1

\begin{tabular}{|c|c|c|c|}
\hline \multirow{2}{*}{ States } & 1 & 2 & 3 \\
\hline & Disassembly & Spare & Reassembly \\
\hline$A B C * D$ & -1 & 0 & 0 \\
\hline$A B C D$ & 0 & 0 & 1 \\
\hline$A B D$ & 1 & 0 & -1 \\
\hline C & 0 & 1 & -1 \\
\hline$C^{*}$ & 1 & 0 & 0 \\
\hline Operation & 1 & 2 & 3 \\
\hline Cost (RM) & 0.065 & 0.95 & 0.065 \\
\hline
\end{tabular}

(b) Handset 2

Fig. 5 (a) \& (b): Transition matrices of both handsets, with the associated operation costs.

Table 1: Evaluation results.

\begin{tabular}{llcc}
\hline Descriptions & Handset 1 & Handset 2 \\
\hline Total Cost & 107012.375 & 106237.375 \\
$\mathrm{C}_{1}$ & Site opening & 100000 & 100000 \\
$\mathrm{C}_{2}$ & Disposal & - & - \\
$\mathrm{C}_{3}$ & Storage & - & - \\
$\mathrm{C}_{4}$ & Transportation from Collection Point $(i)$ & 654.5 & 654.5 \\
$\mathrm{C}_{5}$ & Transportation between recovery plants $(j)$ & - & - \\
$\mathrm{C}_{6}$ & Transportation from recovery plants to demand site $(k)$ & 182.875 & 182.875 \\
$\mathrm{C}_{7}$ & Recovery operation & 6175 & 5400 \\
& (Disassembly) & 750 & 325 \\
\multicolumn{1}{l}{$\quad$ (Part replacement) } & 4750 & 4750 \\
$\mathrm{C}_{8}$ & Penalty & 675 & 325 \\
Revenue & - & - \\
Net Profit & 375010 & 375010 \\
\hline Difference & 267997.625 & 268772.625 \\
\hline
\end{tabular}

\section{Discussion}

From the case study presented in previous section, it can be seen that a design of product can be improved in terms of disassemblability by including recovery-related FRs and DPs during the problem definition stage. In the first part of the case study, a typical application of AD was shown and a keypad design that entirely fulfills the product FRs was resulted. Nonetheless, in the sense of recovery potential, the design is not adequate. The design is further enhanced by including additional $\mathrm{FR}_{2}$ and $\mathrm{DP}_{2}$ in the second part of the case study. By comparing both transition matrices, 
Handset 1 can be deemed to have a more complicated recovery operation procedure in the event of replacing a faulty keypad. Besides that, for each handset design, the mathematical method presented by Kwak and Kim [2] has been used to obtain the profit of recovery process. Handset 2 is likely to have a higher recovery potential since the results show that it has a profit surplus of RM 775 as compared with that of Handset 1.

\section{Conclusion}

The main purpose of this paper is to demonstrate the usage of AD in improving a keypad design of handsets in terms of recovery potential through a case study. The case study started with applying AD typically to produce a keypad design (denoted Handset 1). This is followed by an improved revision of the design by having additional recovery-related FRs and DPs (denoted Handset 2). A series of design evaluation is performed to enable a comparison between the two resulted handset designs, considering a scenario of replacing faulty keypads. The results obtained by using methodology proposed by Kwak and Kim [2] show that there is a discrepancy in recovery profit caused by architectural difference.

"Can axiomatic design be utilized to increase end-of-life recovery profit?" A simple case study and the evaluation results shown in the form of recovery costs can undoubtedly be used to answer this research question. It can be concluded that recovery profit of a product (mobile phone in this case) can be increased by incorporating additional FRs and DPs to address the recovery-related concerns when defining a design problem using the axiomatic system.

\section{Acknowledgement}

The authors gratefully acknowledge the financial support from the Ministry of Higher Education, Malaysia under grant no. ERGS Vot E024.

\section{References}

[1] K. Ramani, D. Ramanujan, W. Z. Bernstein, F. Zhao, J. Sutherland, C. Handwerker and J. K. Choi, Integrated Sustainable Life Cycle Design: A Review, Journal of Mechanical Design. 132 (2010) 1-15.

[2] M. Kwak and H. M. Kim, Evaluating End-of-Life Recovery Profit by a Simultaneous Consideration of Product Design and Recovery Network Design, Journal of Mechanical Design. 132 (2010) 1-17.

[3] S. K. Fixson, Assessing Product Architecture Costing: Product Life Cycles, Allocation Rules, and Cost Models, Paper presented at ASME 2004 Design Engineering Technical Conferences (2004).

[4] N. P. Suh, The Principles of Design, Oxford University Press, New York, 1990.

[5] S. Finger and J. R. Dixon, A Review of Research in Mechanical Engineering Design. Part I: Descriptive, Prescriptive, and Computer-Based Models of Design Processes, Research in Engineering Design. 1 (1989) 51-67.

[6] G. J. Park, Analytic Methods for Design Practice, Springer, 2007.

[7] C. S. Yu and S. J. Lee, Method for Keypad Optimization, Patent No. US 7551162 B2, 2009.

[8] J. Fedorjaka, Metal Dome Switch Assembly with Enhanced Snap Ratio, Patent No. US 7378609 B1, 2008.

[9] Y. Okamoto and K. Sako, Movable Contact Unit for Panel Switch and Panel Switch Using the Same, Patent No. 5986228, 1999.

[10] K. Z. Chen, Development of Integrated Design for Disassembly and Recycling in Concurrent Engineering, Integrated Manufacturing Systems. 12 (2001) 67 - 79. 